\title{
A systematic review of early prognostic factors for persistent pain following acute orthopedic trauma
}

\author{
Fiona J Clay PhD MSc BSc Grad Dip Epidemiology and Biostatistics ${ }^{1}$, Wendy L Watson PhD MA Dip Ed BSc(Hons) BA², \\ Stuart V Newstead PhD MSc BSc(Hons) AStat ${ }^{1}$, Roderick J McClure PhD MBBS BA ${ }^{1}$
}

FJ Clay, WL Watson, SV Newstead, RJ McClure. A systematic review of early prognostic factors for persistent pain following acute orthopedic trauma. Pain Res Manage 2012;17(1):35-44.

BACKGROUND: Acute orthopedic trauma contributes substantially to the global burden of disease.

OBJECTIVES: The present systematic review aimed to summarize the current knowledge concerning prognostic factors for the presence of persistent pain, pain severity and pain-related disability following acute orthopedic trauma involving a spectrum of pathologies to working-age adults. METHODS: The Ovid MEDLINE and EMBASE databases were searched for level II prognostic studies published between January 1996 and October 2010. Studies that were longitudinal and reported results with multivariate analyses appropriate for prognostic studies were included. Studies that addressed two specific injury types that have been the subject of previous reviews, namely, injuries to the spinal column and amputations, were excluded.

RESULTS: The searches yielded 992 studies; 10 studies met the inclusion criteria and were rated for methodological quality. Seventeen factors were considered in more than one cohort. There was strong evidence supporting the association of female sex, older age, high pain intensity, preinjury anxiety or depression, and fewer years of education with persistent pain outcomes. There was moderate evidence supporting the association between postinjury depression or anxiety with persistent pain, and that injury severity was not a risk factor for ongoing pain.

CONCLUSION: Many individuals experience persistent pain following acute trauma. Due to the lack of studies, the use of different constructs to measure the same factor and the methodological limitations associated with many of the studies, the present review was only able to reliably identify a limited set of factors that predicted persistent pain. Recommendations for the conduct of future methodologically rigorous studies of persistent pain are provided.

Key Words: Acute trauma; Biopsychosocial prognosis; Orthopedic; Pain measurement; Pain outcomes; Systematic review

Tn Australia and Canada, and in some European countries, chronic or persistent pain is prevalent (1-3), with chronic pain prevalence estimates ranging from $10.1 \%$ to $55.2 \%$ (2). Chronic pain is associated with work disability and increased health service utilization, and is a major source of costs to the economy, health systems, injury compensation schemes and society (2-5). Acute orthopedic trauma is a common reason for hospitalization (6) and is often associated with persistent pain and pain-related disability (7). Variation in pain outcomes following acute trauma is reported, and there is uncertainty about which patients are at risk of an adverse pain outcome.

Because the biopsychosocial determinants associated with variation in long-term pain outcomes following acute orthopedic trauma are poorly understood, the treating clinician is faced with uncertainty when providing prognostic advice regarding long-term recovery. A synthesis of the research evidence on the risk factors associated with adverse pain outcomes should facilitate the early identification of individuals at risk of pain chronicity and, therefore, in need of further management. While biological factors associated with chronic pain are likely to be related to specific injury diagnoses, psychological

\author{
Une analyse systématique des facteurs pronostiques \\ précoces de douleur persistante après un \\ traumatisme orthopédique aigu
}

HISTORIQUE : Les traumatismes orthopédiques aigus contribuent sensiblement au fardeau global de la maladie.

OBJECTIFS : La présente analyse systématique visait à résumer les connaissances actuelles sur les facteurs pronostiques de présence de douleur persistante, de gravité de douleur et d'invalidité liée à la douleur après un traumatisme orthopédique aigu touchant un spectre de pathologies chez des adultes en âge de travailler

MÉTHODOLOGIE : Les auteurs ont effectué des recherches dans les bases de données Ovid de MEDLINE et d'EMBASE pour extraire les études pronostiques de niveau II publiées entre janvier 1996 et octobre 2010, y compris les études longitudinales et les analyses multivariées convenant aux études pronostiques. Les études portant sur deux types de blessures précises qui avaient fait l'objet d'analyses antérieures, soit les blessures à la colonne vertébrale et les amputations, étaient exclues.

RÉSULTATS : Les recherches ont permis d'extraire 992 études, dont dix respectaient les critères d'inclusion et dont la qualité méthodologique a été évaluée. Ils ont tenu compte de 17 facteurs dans plus d'une cohorte. Des données solides soutenaient l'association du sexe féminin, d'un âge avancé, d'une forte intensité de douleur, d'anxiété ou de dépression avant la blessure et d'une moins grande scolarisation accompagnant les issues de douleur persistante. Des données modérées soutenaient l'association entre la dépression ou l'anxiété après la blessure et la douleur persistante et le fait que la gravité de la blessure ne constituait pas un facteur de risque de douleur continue.

CONCLUSION : De nombreuses personnes ressentent des douleurs persistantes après un traumatisme aigu. Étant donné l'absence d'études, le recours à divers construits pour mesurer le même facteur et les limites méthodologiques associées à bon nombre de ces études, la présente analyse n'a pu déterminer avec fiabilité qu'un ensemble limité de facteurs prédictifs d'une douleur persistante. Des recommandations relatives à la tenue de futures études sur la douleur persistante, rigoureuses sur le plan méthodologique, sont présentées.

and socioenvironmental factors should be common to a wide spectrum of acute traumatic injuries.

Previous reviews addressing determinants of chronic pain outcomes secondary to acute trauma have primarily focused on specific injury samples related to structures of the spine, including spinal cord injury and whiplash-associated disorders, or have addressed outcomes following limb amputations (8-11). These reviews report a lack of consistency with respect to the important prognostic factors. One systematic review was more generic, focusing on polytrauma including traumatic brain injury (12). However, this review focused on painrelated rather than pain-specific outcomes; it also included many studies that did not report multivariate analyses and did not provide information on the magnitude of effect. This limits the meaningful evidence on prognostic factors that can be drawn from the review.

Limiting a review to a specific biological injury potentially decreases the power and generalizability of the findings. This is because acute orthopedic injuries do not reflect single disease entities but include a complex spectrum of pathologies, causes, severities and baseline prognostic risk of adverse long-term outcomes (13).

${ }^{1}$ Monash University, Monash Injury Research Institute, Clayton Campus, Victoria; ${ }^{2}$ New South Wales Injury Risk Management Research Centre, University of New South Wales, Sydney, New South Wales, Australia

Correspondence: Professor Roderick McClure, Monash University, Monash Injury Research Institute, Building 70, Clayton Campus, Victoria 3800, Australia. Telephone 61-3-9905-4372, fax 61-3-9905 4363, e-mail Rod.McClure@monash.edu 
Furthermore, there may be concurrent injury to multiple body parts or systems that result in a range of impairments. The International Mission for Prognosis and Analysis of Clinical Trials in Traumatic Brain Injury (TBI-IMPACT) investigated methodologies for dealing with injury heterogeneity (14). Substantial gains in statistical power followed covariate adjustment, and this was more efficient than analyses targeted to clinically defined prognostic groups (13).

Given the problems associated with persistent pain, the number of people requiring hospitalization following traumatic injury and the limited generalizability of findings from previous reviews, a formal synthesis of the current knowledge was warranted. The specific aim of the present review was to identify the early prognostic factors associated with variation in persistent pain outcomes following acute orthopedic trauma presenting with a spectrum of pathologies.

\section{METHODS}

\section{Search strategy}

The Ovid MEDLINE and EMBASE databases were searched for relevant studies published between January 1996 and October 2010. Search terms were mapped to $\mathrm{MeSH}$ terms or subject headings and synonyms were grouped using Boolean operators. A prognostic sensitive filter was applied and the search strategy was developed with the assistance of a specialist subject librarian. A detailed description of the search strategy applied to the Ovid MEDLINE database is provided in Appendix 1. The reference lists of all relevant articles were screened for additional publications.

Results of the database searches were downloaded into Endnote X2 (Endnote, USA) and duplicate articles were excluded. One reviewer (FJC) initially screened all titles and abstracts for potential relevance. Full-text articles considered to be relevant, together with articles where there was uncertainty as to their relevance, were screened by two authors (FJC, RM) and a decision made as to which articles should be retained. Disagreements were resolved by consensus.

\section{Outcomes}

Because of the nature of pain, the reported outcomes are many and varied. Because the focus of the present review was on determinants of persistent pain, only patient-focused outcomes that specifically referred to pain were considered. For example, if the outcome was the presence of persistent pain or pain severity, the study was included. Examples of these may include a visual analogue scale or a pain scale that forms part of a questionnaire (eg, the pain or discomfort item from the EQ-5D [EuroQol Group, The Netherlands]). If it was a summary measure of disability postinjury, such as the Short Form-36 Physical Component Summary score that did not identify and analyze an explicit measure of pain, it was not included in the review.

\section{Definition of injury}

The following definition of injury was applied to studies included in the present review.

Injury was defined as damage to the body "resulting from the transfer of environmental energy to a person at levels that exceed the threshold for tissue damage" (15). Injury was further defined according to the International Classification of Disease ICD-10-AM S and T injury diagnosis codes (16). Orthopedic injury is defined as an injury affecting the body's musculoskeletal system, and includes injuries to bones, joints, ligaments, tendons, muscles and nerves (17). Orthopedic injuries may results from acute or chronic exposures; however, the focus of the present review is on orthopedic injuries resulting from acute exposures.

\section{Inclusion and exclusion criteria}

The present review was limited to studies published in English and available as full-text articles. Only prospective and retrospective cohort studies were considered. Articles were selected for inclusion according to the following criteria:

- The primary research question addressed the determinants of persistent pain, the study design was longitudinal (prospective or retrospective [18]) and the article reported results with multivariate statistical analyses appropriate to prognostic studies.

- Samples included persons of working age, defined as 15 to 70 years of age.

- Because factors collected in the early stages of recovery following an injury are the most useful to guide rehabilitation, only factors measured proximal to the injury either preinjury or the early postinjury phase were included (defined as within 30 days of the date of injury).

- The International Association for the Study of Pain defines chronic pain as pain without biological value that has persisted beyond the normal healing time. This may be less than one month to more than six months, with three months being considered a convenient point of division between acute and chronic pain (19). In keeping with this definition, pain outcomes had to be measured at least three months following the date of injury. The terms 'chronic' or 'persisting' pain are used interchangeably throughout the present review.

The following studies were excluded:

- Studies of pain related to the spinal column, because these studies have received consideration in recent reviews. These include studies of back pain, spinal cord injury, neck pain and whiplashassociated disorder.

- Studies of pain-related limb amputations. The phenomenon of phantom limb and residual limb pain following a traumatic amputation is well documented (20). The sequelae associated with amputations are such that these conditions are less comparable with pain following other orthopedic injuries.

- Studies of fractures secondary to disease.

- Studies examining specific clinical management approaches or interventions.

- To rule out findings with low statistical power that may not be broadly representative of the biopsychosocial nature of pain or that may be due to chance variation in the data, studies were excluded if the sample size analyzed with respect to the pain was fewer than 80.

- Studies that did not sufficiently recognize the biopsychosocial nature of pain. The biopsychosocial nature of persistent pain recognizes that the experience and impact of pain is determined through the interaction of three main groups of personal factors, namely, biological, psychological and socioenvironmental factors (4). To prevent unnecessary pain-related disability, as many of these factors as possible should be addressed in interventions (4). A study that would be excluded is one that examined the determinants of persistent pain outcomes and included in multivariate models only clinical data from the initial inpatient postinjury episode (21).

\section{Quality assessment}

The quality of the included studies was rated according to the $12 \mathrm{cri}$ teria outlined in Table 1 . The criteria were adapted from a review by Hayden et al (22), and address the six major sources of bias in prognostic reviews $(22,23)$. The quality assessment addressed potential bias in the form of study participation, the measurement of outcome, prognostic factor measurement and statistical analysis. Two authors independently assessed the quality of each included study. The 12 criteria were answered 'yes', 'no' or 'unsure'; only scores of yes contributed to the overall quality score. The quality assessment criteria are further outlined in a systematic review of factors associated with return to work by the first author (24). Studies that scored 10 or more points were rated as high quality, those that achieved seven to nine points were considered moderate quality and studies with less than seven points were rated as low quality. No studies were excluded on the basis of quality.

\section{Level of evidence}

The strength of the evidence of prognostic factors was determined according to a rating system similar to that used by Clay et al (24). The 
TABLE 1

\section{Quality assessment criteria used in the present review}

\begin{tabular}{l} 
Sample \\
\hline S1 The study was an inception cohort \\
S2 Inception time point was explicitly stated \\
S3 Study provided clearly defined inclusion and exclusion criteria \\
S4 The setting and study site were clearly described \\
Prognostic factors \\
\hline P1 Clearly defined and justified constructs of what was measured was \\
provided \\
P2 Descriptive data for most prognostic factors were provided \\
Follow-up \\
FU1 The data were complete for at least $80 \%$ of the sample measured at \\
$\quad$ baseline. If a retrospective study, there should be less than 10\% \\
missing data \\
FU2 Pain outcomes were defined in detail \\
Analysis \\
\hline A1 The analysis was sufficiently powered to test the study hypotheses \\
A2 Enough information was provided to interpret the results \\
A3 Enough information was provided to know whether the assumptions of \\
the multivariate technique were met \\
A4 Evidence of adequate adjustment for common confounders
\end{tabular}

TABLE 2

Levels of evidence for individual factors in the present review

\begin{tabular}{ll}
\hline Level of evidence & Criteria for evidence level \\
\hline $\begin{array}{l}\text { Strong } \\
\text { Moderate }\end{array}$ & $\begin{array}{c}\text { Consistent findings in at least } 2 \text { high-quality cohorts } \\
\text { One high-quality cohort and consistent findings in one } \\
\text { or more low-quality cohorts }\end{array}$ \\
Limited & $\begin{array}{c}\text { Findings of one cohort or consistent findings in one or } \\
\text { more low-quality cohorts }\end{array}$ \\
Inconsistent & Inconsistent findings irrespective of study quality
\end{tabular}

levels of evidence are outlined in the Table 2. For the level of evidence to be considered strong, findings had to be consistent in at least two high-quality studies. When the findings were from only one study, the level of evidence was considered to be limited. A positive effect of a factor in one study and a negative effect in another were rated as an inconsistent finding. A significant effect of a factor in one study and a nonsignificant association in another were rated as consistent findings provided that the effect sizes were in a similar direction.

\section{Data extraction}

The following data were extracted as they appeared in the original publication: study population and setting, sample size included in the analysis, nature of injuries, inclusion and exclusion criteria, study design, outcome definition, follow-up time points, prevalence of pain, loss to follow-up and missing data (if retrospective study), analytic method, and significant and nonsignificant factors identified in multivariate analyses. Only factors measured proximal to the injury are reported. Factors were considered to be significant determinants at $\mathrm{P}<0.05$. Due to the potential for confounding to invalidate the findings associated with factors reported as significant at the univariate level, only factors included in multivariate analyses are reported.

\section{RESULTS}

Study selection

The search strategy resulted in an initial yield of 979 references from the two databases. A further 13 potentially relevant references were identified from the reference lists of articles. After removal of duplicate references, 928 references remained. Of these, 883 references were excluded based on either title or abstract. The full text of 45 articles was retrieved for detailed evaluation; 27 did not meet the

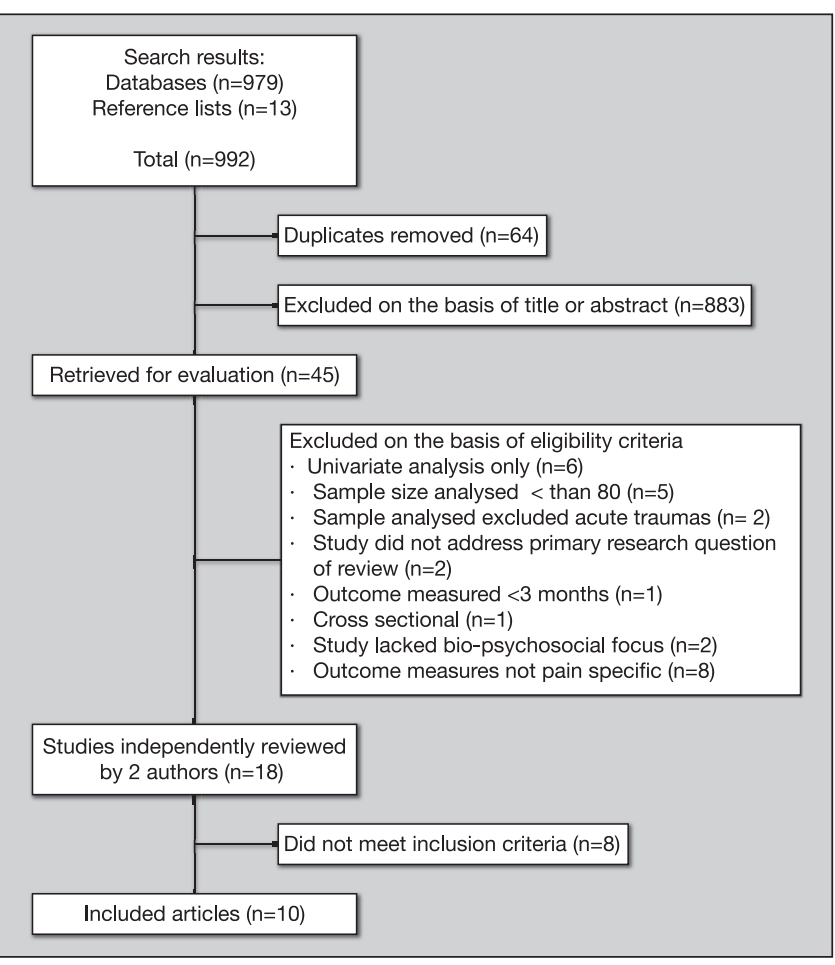

Figure 1) Flow diagram for retrieval of studies for the present systematic review

inclusion criteria. Reasons for exclusion included that the study did not report multivariate analyses, the sample size analyzed was less than 80 , the sample excluded acute trauma patients, the outcome was measured before three months postinjury, the study was cross-sectional or the study did not adequately consider the biopsychosocial nature of pain. After independent review by two authors, a further eight articles were excluded, leaving 10 articles in the review. The search strategy is outlined in Figure 1.

\section{Quality assessment}

The quality assessment revealed methodological problems with many studies including insufficient justification of measures and constructs, analyses lacking power to achieve statistical significance with the available sample size, lack of reporting on the extent of missing data, and insufficient reporting on the detail of the statistical analysis including the precise form of regression analysis carried out and whether the assumptions associated with the regression technique were met. Three studies were rated as high quality $(30,33,34)$, five as moderate quality $(25,26,29,31,32)$ and two as low quality $(27,28)$. Table 3 summarizes information on the studies including the country, setting, nature of the injuries, inclusion and exclusion criteria, study design, outcome definition and follow-up time points. Table 4 summarizes the quality assessment score.

\section{Summary features of the included studies}

The 10 studies included in the final review evaluated four different pain outcomes: presence of pain, presence of pain or discomfort, pain severity and pain interference with activities. Of the six different measures used to assess pain outcomes; only two were developed with a primary focus on pain (Chronic Pain Grade and Graded Chronic Pain questionnaires) $(30,34)$. Nine of the 10 studies included in the present review were based on inception cohorts. Participant follow-up occurred between six months and seven years postinjury. Using criteria of $80 \%$ follow-up, only two of the studies had acceptable loss to follow-up $(29,30)$. Given the extended period of follow-up in the study by Castillo et al (34), $28 \%$ loss to follow-up appears reasonable. Most of the injury samples consisted of trauma with an injury severity score (ISS) of 10 or higher (35). No studies were identified that only included individuals with ISS minor 
TABLE 3

Characteristics of included studies

\begin{tabular}{|c|c|c|c|c|c|c|c|c|c|}
\hline $\begin{array}{l}\text { Author } \\
\text { (ref), year }\end{array}$ & Country & Setting & $\begin{array}{l}\text { Nature of } \\
\text { injuries }\end{array}$ & Inclusion criteria & Exclusion criteria & $\begin{array}{l}\text { Study } \\
\text { design }\end{array}$ & $\begin{array}{c}\text { Outcome } \\
\text { measurement }\end{array}$ & $\begin{array}{l}\text { Outcome } \\
\text { definition }\end{array}$ & $\begin{array}{l}\text { Follow-up } \\
\text { time-point }\end{array}$ \\
\hline $\begin{array}{l}\text { Andrews et } \\
\text { al (25), } \\
2008\end{array}$ & AUS & $\begin{array}{l}\text { Victorian } \\
\text { Orthopaedic } \\
\text { Trauma } \\
\text { Outcomes } \\
\text { Registry }\end{array}$ & $\begin{array}{l}\text { Orthopedic } \\
\text { injuries } \\
\text { ISS }<16: \\
83.1 \%\end{array}$ & $\begin{array}{l}\text { 15-74 years of age } \\
\text { Sports and active recreation } \\
\text { injury } \\
\text { Admitted August } 2003 \text { to } \\
\text { March } 2006\end{array}$ & $\begin{array}{l}\text { Workers compensation } \\
\text { cases }\end{array}$ & Pros & $\begin{array}{l}\text { Numerical } \\
\text { Rating Scale }\end{array}$ & $\begin{array}{l}\text { Moderate or } \\
\text { severe pain }\end{array}$ & 12 months \\
\hline $\begin{array}{l}\text { Williamson } \\
\text { et al (26), } \\
2009\end{array}$ & & & $\begin{array}{l}\text { Orthopedic } \\
\text { injuries }\end{array}$ & $\begin{array}{l}\text { Injury managed by an } \\
\text { orthopaedic unit } \\
\text { Spinal injury } \\
\text { Admitted } 2003 \text { to } 2006\end{array}$ & $\begin{array}{l}\text { Isolated injury not } \\
\text { managed by an } \\
\text { orthopedic unit } \\
\text { Fracture secondary to } \\
\text { cancer }\end{array}$ & & & & 6 months \\
\hline $\begin{array}{l}\text { Ulvix et al } \\
\qquad(27) \\
2008\end{array}$ & NOR & Hospital & Major trauma & $\begin{array}{l}18 \text { years or older } \\
\text { ICU admission }\end{array}$ & Foreign visitors & Retro & EuroQol & $\begin{array}{c}\text { EQ-4 pain or } \\
\text { discomfort }\end{array}$ & $2-7$ years \\
\hline $\begin{array}{l}\text { Jenewein } \\
\text { et al (28), } \\
2008\end{array}$ & SWITZ & Hospital & $\begin{array}{l}\text { Injury } \\
\text { requiring } \\
\text { ICU } \\
\text { admission } \\
\text { ISS } \geq 10\end{array}$ & $\begin{array}{l}\text { 18-70 years } \\
\text { ISS } \geq 10 \text { and } G C S \geq 9 \\
\text { Well enough to participate } \\
\text { within } 1 \text { month of injury, } \\
\text { German speaking }\end{array}$ & $\begin{array}{l}\text { Suffering from serious } \\
\text { somatic illness } \\
\text { Under treatment for a } \\
\text { mental disorder before } \\
\text { the injury }\end{array}$ & Pros & $\begin{array}{l}\text { Single item } \\
\text { question }\end{array}$ & $\begin{array}{l}\text { Presence of } \\
\text { pain }\end{array}$ & 36 months \\
\hline $\begin{array}{l}\text { Holtsag et } \\
\text { al (29), } \\
2006\end{array}$ & NL & Hospital & $\begin{array}{l}\text { Severe } \\
\text { injuries } \\
\text { ISS } \geq 16\end{array}$ & ISS $>16$ & None specified & Pros & EuroQol & $\begin{array}{c}\text { EQ-4 pain or } \\
\text { discomfort }\end{array}$ & $\begin{array}{l}15.5 \\
\text { months } \\
\text { Mean } \pm \\
\text { SD } \\
451 \pm 47 \\
\text { days) }\end{array}$ \\
\hline $\begin{array}{l}\text { Holmes et } \\
\text { al (31), } \\
2010\end{array}$ & AUS & $\begin{array}{l}\text { Trauma } \\
\text { hospital }\end{array}$ & $\begin{array}{l}\text { Various } \\
\text { Mean } \\
\text { ISS }=12.3 \\
(\mathrm{SD}=8.5)\end{array}$ & $\begin{array}{l}\text { At least one injury with } \\
\text { AIS } \geq 2 \\
18-70 \text { years of age, no brain } \\
\text { injury } \\
\text { Hospital admission }>24 \mathrm{~h} \\
\text { Assessed within } 14 \text { days of } \\
\text { injury }\end{array}$ & $\begin{array}{l}\text { Injury due to a non- } \\
\text { height fall } \\
\text { Moderate or severe head } \\
\text { injury } \\
\text { Suicidal or psychotic. } \\
\text { Pre-existing cognitive } \\
\text { impairment }\end{array}$ & Pros & $\begin{array}{l}\text { Numerical } \\
\text { Rating Scale }\end{array}$ & $\begin{array}{l}\text { Pain severity } \\
\text { currently and } \\
\text { over last } \\
24 \mathrm{~h}\end{array}$ & 3 months \\
\hline $\begin{array}{l}\text { Rivara et al } \\
(30) \\
2008\end{array}$ & USA & $\begin{array}{l}\text { Trauma } \\
\text { centres }\end{array}$ & $\begin{array}{l}\text { Various } \\
\text { ISS } \geq 9\end{array}$ & Injury with an AIS $\geq 3$ & $\begin{array}{l}\text { Burns } \\
\text { First listed hip fracture } \\
\text { diagnosis } \\
\text { Delayed care for } 24 \mathrm{~h} \\
\text { Did not speak English or } \\
\text { Spanish }\end{array}$ & Pros & $\begin{array}{l}\text { SF36 } \\
\text { Chronic Pain } \\
\text { Grade }\end{array}$ & $\begin{array}{l}\text { Pain } \\
\text { prevalence } \\
\text { Pain severity }\end{array}$ & 12 months \\
\hline $\begin{array}{l}\text { Hoffman et } \\
\text { al (33), } \\
2007\end{array}$ & USA & $\begin{array}{l}\text { Acute } \\
\text { inpatient } \\
\text { rehabilitation }\end{array}$ & TBI & $\begin{array}{l}\text { Primary diagnosis of TBI } \\
16 \text { years of age or older } \\
\text { ED arrival within } 24 \mathrm{~h} \text { of injury } \\
\text { Acute/postacute care within } \\
\text { Model system of care }\end{array}$ & None specified & Pros & $\begin{array}{l}\text { SF36 bodily } \\
\text { pain scale }\end{array}$ & $\begin{array}{l}\text { Pain intensity } \\
\text { Pain } \\
\text { interference } \\
\text { with normal } \\
\text { work } \\
\text { activities }\end{array}$ & 1 year \\
\hline $\begin{array}{l}\text { Castillo et } \\
\text { al (34), } \\
2006\end{array}$ & USA & $\begin{array}{l}\text { Trauma } \\
\text { centres }\end{array}$ & $\begin{array}{l}\text { Lower } \\
\text { extremity } \\
\text { trauma }\end{array}$ & $\begin{array}{l}\text { 18-69 years of age } \\
\text { Trauma below the distal femur } \\
\text { Severe foot injuries } \\
\text { Major soft tissue injury } \\
\text { Dysvascular limb injury } \\
\text { Gustilo open fracture } \\
\text { classification: Grade IIIb-IIIc, } \\
\text { some IIla }\end{array}$ & $\begin{array}{l}\text { Spinal cord deficit } \\
\text { rThird-degree burns } \\
\text { Not resident in catchment } \\
\text { area } \\
\text { GCS }<15 \text { at } 21 \text { days or } \\
\text { discharge } \\
\text { On active military duty } \\
\text { Documented psychiatric } \\
\text { disorder } \\
\text { Prior leg or foot amputation } \\
\text { Treatment delay of }>24 \mathrm{~h}\end{array}$ & Pros & $\begin{array}{l}\text { Graded } \\
\text { Chronic Pain } \\
\text { Questionnaire }\end{array}$ & $\begin{array}{l}\text { Pain } \\
\text { interference } \\
\text { with work } \\
\text { activities }\end{array}$ & 7 years \\
\hline
\end{tabular}

AIS Abbreviated injury scale; AUS Australia; ED Emergency department; EQ EuroQol; FRAN France; GCS Glasgow coma score; ICU Intensive care unit; ISS Injury severity score; NISS New injury severity score; NL Netherlands; NOR Norway; Pros Prospective; ref Reference; Retro Retrospective; SF36 Short Form-36; SWITZ Switzerland; TBI Traumatic brain injury; USA United States 
TABLE 4

Results from the included studies

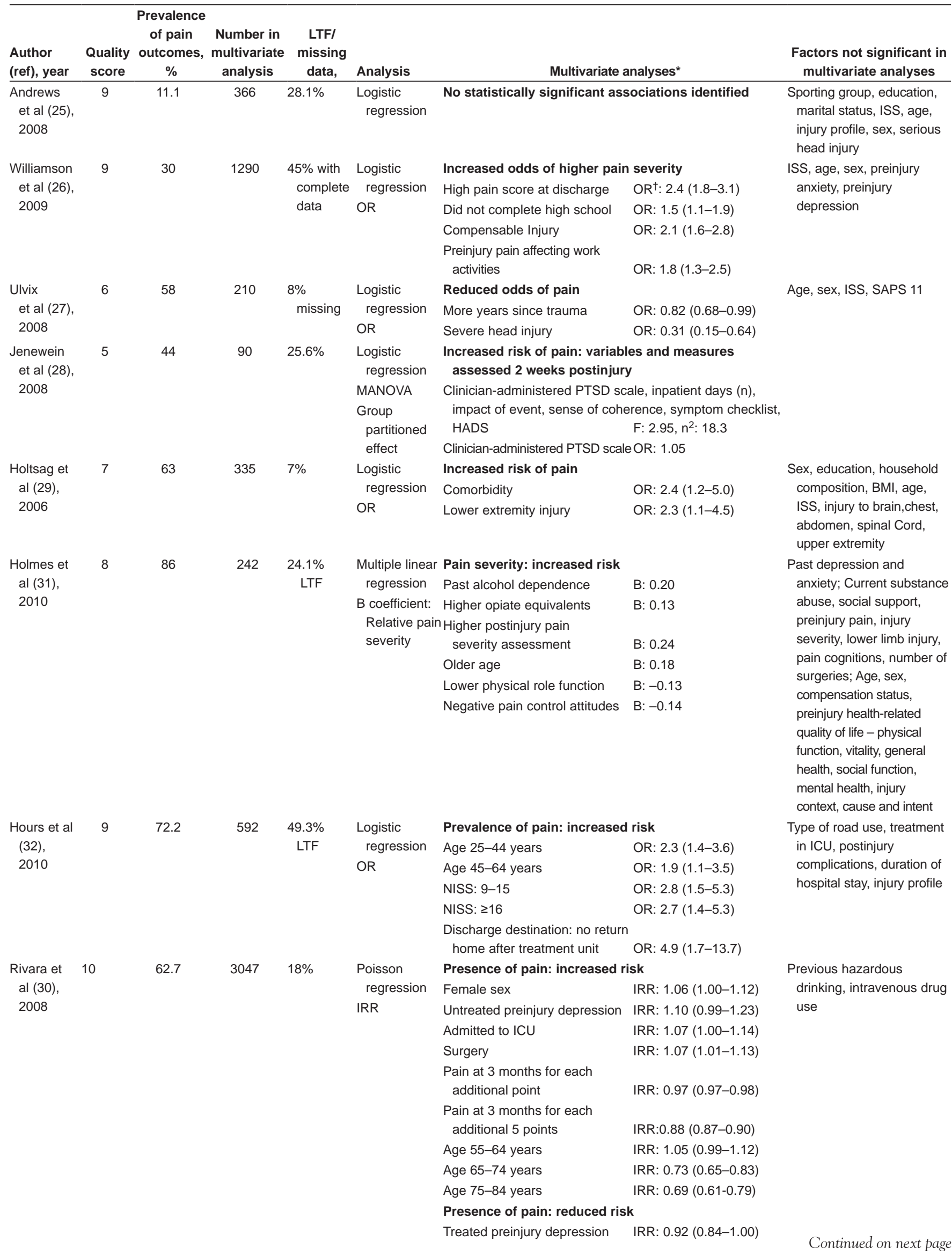


TABLE 4 - CONTINUED

Results from the included studies

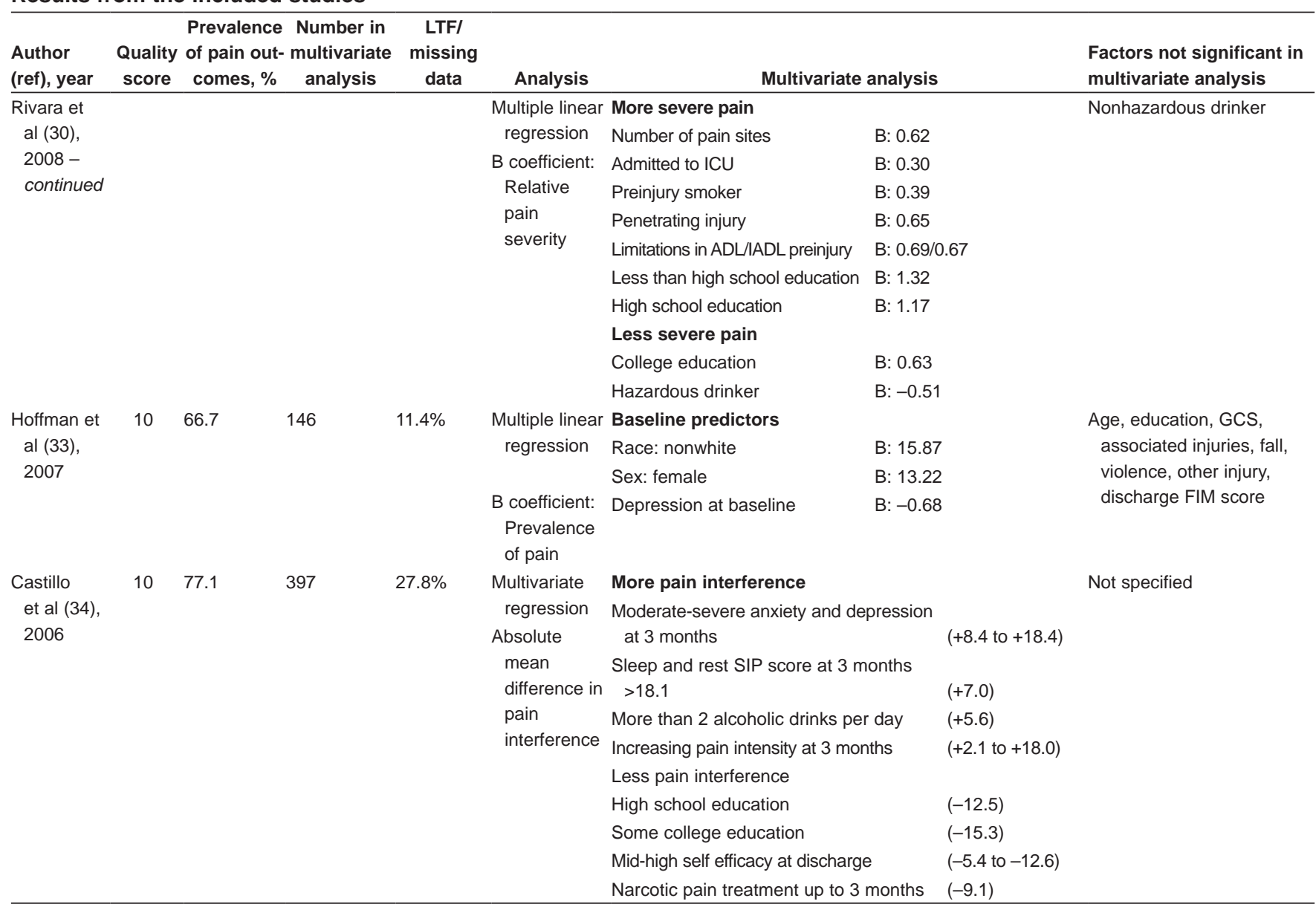

${ }^{*}$ Significant at $P<0.05 ;{ }^{\dagger}$ Numbers in parentheses after ORs are $95 \% \mathrm{Cls}$. ADL Activities of daily living, BMI Body mass index; FIM Functional Independence Measure; GCS Glasgow coma score; HADS Hospital Anxiety and Depression Scale; IADL Instrumental activities of daily living; ICU Intensive care unit; IRR Incidence rate ratio; ISS Injury severity score; LTF Lost to follow-up; NISS New injury severity score; PTSD Posttraumatic stress disorder; ref Reference; SAPS Severity Acute Physiology Scale; SIP Sickness Impact Profile

injuries (ISS: 1 to 8). Depending on the nature of the injured sample as well as the time point and method of outcome measurement, the prevalence of pain following acute orthopedic trauma for studies included in the present review ranged from $11 \%$ to $77 \%$. Two studies were based on the same time period of recruitment from the same orthopedic trauma registry $(25,26)$. Each study selected subsamples of the registry cohort using different inclusion and exclusion criteria but used the same outcome measures and analytic approach techniques. For the remainder of the present review, they will be described as subset analyses of a single cohort.

Assessment of statistical analysis

An inclusion criterion for studies in the present review was that the publication reported results with statistical analysis techniques appropriate to prognostic studies. A number of studies used stepwise elimination multivariate regression techniques and did not report information on factors that were not statistically significant in the model $(22,23,26,28,34)$ such as the estimated effect size and standard deviation before elimination from the model or change in model fit on removal of the factor. For those studies, it was not possible to assess whether the analysis was sufficiently powered to be able to test the study hypotheses. A number of studies used multivariate linear regression to assess the determinants of pain severity but did not test for the normality of the residuals $(30,31,33)$. At least one moderate-quality study appeared underpowered because no statistically significant associations were detected even though the estimated effect sizes for a number of factors were of clinically interesting magnitude (25). In a number of studies, insufficient detail was provided to be able to fully understand the analytic method, make an appropriate assessment of the statistical quality or to fully understand the results $(28,30-32,34)$. Some studies failed to identify potential colinearity between included factors. For example, the inclusion of two closely related measures of posttraumatic symptoms in the same MANOVA model is potentially subject to problems with collinearity (28). Data pooling was not possible due to the heterogeneity of outcome definitions, follow-up time points, covariate classifications and methods. Features of the statistical analysis including the number of observations included in analyses, the regression technique used and the significant and nonsignificant factors as reported in the multivariate analyses are reported in Table 4.

Levels of evidence

The evidence for specific factors identified in studies included in the present review will now be outlined. Only generic factors that would be relevant to multiple contexts are reported. Factors related to specific injury subsets in the study by Castillo et al (34) are not included. The classifications that were used are arbitrary; some factors could potentially be included under more than one classification. While more than 70 individual factors were examined in studies included in the present review, only 17 factors were considered in 
TABLE 5

Level of evidence for individual factors measured in more than one cohort

\begin{tabular}{|c|c|c|c|c|}
\hline Prognostic factor & Level of evidence & $\begin{array}{l}\text { Direction of association with } \\
\text { adverse pain outcomes* }\end{array}$ & $\begin{array}{l}\text { Reference(s) of } \\
\text { included studes }\end{array}$ & $\begin{array}{l}\text { Reference(s) in which no statistical } \\
\text { association with } \mathrm{P}<0.05 \text { was found }\end{array}$ \\
\hline Age: older & Strong & Increased & $30-32$ & $33,25-27,29,31$ (aged $\geq 65$ years) \\
\hline Female sex & Strong & Increased & 30,33 & $25-27,28,29,32$ \\
\hline Injury Severity Score: higher & Moderate $^{\dagger}$ & Increased & 32 & $25-27,29,31$ \\
\hline Compensable injury & Moderate & Increased & 26 & 31 \\
\hline Treatment in intensive care unit & Moderate & Increased & 30 & 32 \\
\hline Substance abuse & Moderate & No association & - & 30,32 \\
\hline High pain intensity & Strong $^{\dagger}$ & Increased & $26,30,31,34$ & - \\
\hline Preinjury depression or anxiety: untreated & Strong $^{\dagger}$ & Increased & 30,33 & 26,31 \\
\hline Serious head injury & Limited $^{\dagger}$ & Decreased & 27 & 25 \\
\hline Injury profile & Moderate & No association & - & $26,29,32$ \\
\hline Mechanism of injury & Moderate & No association & - & 31,33 \\
\hline \multirow[t]{2}{*}{ Hazardous alcohol drinker } & Inconsistent $^{\dagger}$ & Decreased & 30 & - \\
\hline & & Negative & 31,34 & - \\
\hline
\end{tabular}

${ }^{*}$ Increased or decreased likelihood of an adverse pain outcome relative to the criterion selected as the reference category; ${ }^{\dagger}$ Different constructs used to measure prognostic factor

more than one cohort. An overview of the evidence for factors measured in more than one cohort is presented in Table 5.

\section{Prognostic factors}

Sociodemographic factors: Age and sex were investigated in all studies included in the present review. One high-quality study and two moderate-quality studies reported an association between age and pain (30-32); no association was identified in the remaining studies. Two high-quality studies reported that female sex was associated with an increased risk of pain $(32,33)$, and five lower-quality studies reported no such association. There was strong evidence from three studies that more years of education was associated with better pain outcomes including less severe pain and less interference with activities $(26,30,34)$. One high-quality and two moderate-quality studies found no association between education and pain $(25,29,33)$. The evidence relating to the consumption of alcohol was inconsistent. Current hazardous drinking was associated with less severe pain at 12 months postinjury in one high-quality study (30), and in a second high-quality study it was associated with greater pain interference with activities (34). Past alcohol dependence was associated with an increased risk of pain in one study (31).

Injury- and treatment-related factors: ISS was examined in six lowerquality studies with only one moderate-quality study reporting a statistically significant association between the new ISS and pain $(25-27,29,31,32)$. The need for surgery were associated with an increased risk of pain but was only evaluated in a single study (30). There was strong evidence from four studies that high pain intensity at discharge or early postinjury was associated with adverse pain outcomes $(26,30,31,34)$. There was limited evidence for the effect of drug treatment on pain outcomes. In one study, treatment with narcotics at an early time-point was associated with better outcomes (34) while a second study reported that ongoing opiate treatment was associated with an increased risk of severe pain (31). A lower extremity injury was associated with an increased risk of pain in one lower-quality study (29) but not in other studies $(31,33)$.

Psychosocial factors: There was strong evidence from two studies that preinjury anxiety or depression was associated with poorer pain outcomes $(30,33)$. One moderate-quality study found no such association
(26). There was moderate evidence from two studies that postinjury anxiety or depression was associated with persisting pain $(28,34)$. One high-quality and one moderate-quality study reported limitations in preinjury instrumental activities of daily living as being predictive of adverse pain outcomes $(26,30)$. Self-efficacy was considered in one high-quality study and was associated with less pain interference with activities (34). Compensation status was associated with pain severity in one moderate-quality study (26), while in a second moderate-quality study no statistical association was found between compensation and poor pain outcomes (31).

\section{DISCUSSION}

In the present review, individuals who were older, female, or who reported preinjury anxiety or depression at recruitment or high pain intensity in the acute postinjury period were more likely to report the presence of persisting pain and other pain-related outcomes. In contrast, persons with higher levels of education had a reduced risk of adverse pain outcomes. While many factors were considered across the 10 studies, the small number of factors considered in more than one cohort limits the conclusions that can be drawn on individual factors. While a comprehensive literature search was performed, only 10 studies were identified that fulfilled the inclusion criteria for the present review.

Seven of the 10 studies had a primary analytic question that focused on pain $(26,28,30-33)$. Two studies were based on data from the same orthopedic trauma outcomes registry cohort $(25,26)$, and while such registries provide a valuable base by which to chart postinjury recovery, the data they collect are generally limited and do not substantively support hypotheses-driven research analyses. The need for additional high-quality research to evaluate a comprehensive range of determinants of persisting pain following acute orthopedic trauma is a key outcome of the present review.

Many of the studies included in the present review had methodological shortcomings. The most common of these was the lack of detail provided on the statistical analyses. This made it difficult to interpret the results effectively, to assess the adequacy of the sample size or to evaluate the possibility of bias associated with loss to follow-up and missing data. The selective reporting of only statistically significant 
associations in many of the articles meant that it was not possible to determine whether the factors that were not significant were due to low statistical power or may have represented potentially important clinically significant results worthy of additional study. The need to improve the statistical rigor associated with pain outcome studies is apparent.

While a number of acute trauma outcome studies that were not included in the present review reported the prevalence of persisting pain, it was surprising how few studies assessed the role of potential determinants of persisting pain in multivariate analyses. This is particularly so given the large volume of research literature that exists in relation to persisting pain of nonspecific etiology. It is possible that because acute trauma is, for the most part, diagnostically specific, pain is an accepted symptom and, as such, the primary focus has been on the immediate medical management of the injury rather than the consideration of long-term pain outcomes. This approach appears more in keeping with a biomedical model that centres on the medical treatment of the pathological causes related to the injury and ensuing disability (36). Support for this proposition comes from a review of studies examining chronic pain secondary to disability including spinal cord injury and traumatic amputations (10). Ehde et al (10) questioned whether persons with chronic pain secondary to disability were regularly identified as having a chronic pain problem.

While the biopsychosocial model of pain has provided a useful conceptual framework that has advanced our understanding of the determinants associated with the variation in pain outcomes $(4,37)$, the majority of studies included in the present review evaluated a simplistic set of factors not well linked to the biopsychosocial model. Findings from studies of chronic pain-related disability as a primary condition highlight the importance of psychological factors in the development and maintenance of pain chronicity (38). While mixed orthopedic injury samples should facilitate the identification of psychological and social factors in common to a range of orthopedic injuries, the studies outlined in the present review considered only a small subset of psychosocial factors. The review identified strong evidence for preinjury anxiety or depression, and moderate evidence for postinjury depression or anxiety as a risk factor for the development of persisting pain. Given the evidence for these factors, it seems reasonable that identifying injured persons with these symptoms may lead to psychological treatment being initiated. The six studies included in the present review that measured depression or anxiety used five different measures of depression or anxiety including self report, Brief Symptom Inventory, Short Form-36, Hospital Anxiety and Depression Scale and the Symptom Checklist-90. The validity of the findings is open to question given that most of the studies included in the present review did not well specify cut-offs that would indicate or enable comparisons between measures or the degree to which the study measured symptoms of minor or major depression. For the prognostic determinants associated with adverse pain outcomes to be of use in clinical care, clear evidence on prognostic determinants established from the inclusion of the same attributes and measures across multiple studies is needed. While the review concluded that there was evidence for pre-existing depression or anxiety symptoms as being associated with the development of persisting pain, further research is needed to determine whether the presence of such symptoms reflects a causal association or act simply as a marker of persisting pain.

Pain is a complex subjective phenomenon with multiple dimensions; the expression of pain often occurs via behaviour including pain intensity, activity, medication use, litigation, work disability and health service utilization (39-41). The present review identified a lack of consistency in the timing and assessment of pain outcomes. The inclusion of a single pain measure or dimension measured on only one occasion may provide an incomplete picture with respect to the problems associated with pain chronicity (40). Composite measures of pain intensity and pain interference serve to indicate a problem but may not well identify the specific dimension(s) associated with the pain. The majority of the studies included in the present review measured pain at only one time-point and used a single pain measure. Given that the personal assessment of pain is highly subjective and subject to recall bias (42), repeated assessments with more than one measure of pain are considered to be critical (40).

\section{Comparison with other reviews}

In a review of chronic pain secondary to disability, Ehde et al (10) noted how few studies in samples of disabled persons had tested the biopsychosocial model. The small number of studies identified in the current review confirms this observation. While pain coping or catastrophizing were associated with adjustment to phantom limb pain following traumatic amputation, many of these studies were cross-sectional and therefore more prone to bias (10). A number of systematic reviews of work-related neck and back pain have identified strong evidence for the role of job demands, job stress, job insecurity and low social support in the development of chronic pain $(43,44)$. The consistent evidence for these factors suggests that they are worth evaluating in an acute trauma cohort. In common with a review of recovery following whiplash-associated disorder (8), the present review identified evidence for the association between early high pain intensity and persisting pain.

\section{Strengths and limitations}

The strength of the present review is that the methodology closely followed the Meta-analysis Of Observational Studies in Epidemiology (MOOSE) guidelines for systematic reviews of observational studies (45). Other strengths include the limiting of inclusion criteria to studies reporting multivariate analyses and, hence, were better controlled for confounding effects in what is a multifactorial problem as well as the exclusion of studies that primarily focused on clinical factors. The multifactorial nature of pain disability is well recognized and clinical factors, when considered alone, have limited power to predict longterm outcome. While every effort was made to include all relevant articles, it is possible that articles were missed due to the terms employed in the search strategy, although the likely miss rate is considered small due to the comprehensive coverage of the databases searched. While studies in which the sample size analysed was less than 80 were excluded, it is possible that these studies, while very small, may have contributed data of potential significance. Excluding studies related to injuries of the spinal column and to traumatic amputation subsets means it may not be possible to generalize our findings to persisting pain following acute injuries of this nature.

\section{Implications for research}

The search strategy identified many studies that had small sample sizes, only reported the prevalence of chronic pain or only included univariate analyses. The 10 studies included in the present review displayed marked differences in the types of injuries, follow-up time periods, demographic characteristics of the study participants, definitions of persistent pain, methods of data collection and the measurement of persistent pain outcomes. In common with other systematic reviews (2), it is likely that the variability in the range of persistent pain outcomes reported for studies included in the current review (11\% to $77 \%$ ) will have been influenced by the heterogeneity apparent in the different study designs and methodology. Furthermore, the heterogeneity highlights the need for more systematic and uniform prospective epidemiological outcome studies to estimate the determinants of persistent pain outcomes. We have provided our recommendations for the methods and reporting of future studies on chronic pain following acute orthopedic trauma (Table 6). The present review identified no discrete studies of the determinants of pain following non-life-threatening, less serious, injuries. While it might be expected that these injuries will be associated with improved outcomes, including a lower prevalence of pain and painrelated disability, because these injuries are common the burden associated with them may be considerable. The ISS was only associated with adverse pain outcomes in one of the included studies; therefore, given this lack of study, it is unknown whether predictors of pain in samples of major trauma or specific serious injuries will also be associated with chronic pain following less-serious injuries. 
TABLE 6

Recommendations for future studies of factors associated with chronic pain outcomes following acute orthopedic trauma

- The study design should be based on an inception cohort (defined as a cohort of injured persons assembled early in the development of their clinical diagnosis)

- The study population should be clearly described to understand the heterogeneity of participant characteristics. There should be adequate adjustment of participants' characteristics for expected outcomes

- The sample size should be adequate to build the model. The number of cases with the outcome of interest and the total number of cases in the sample should be reported

- Selection bias should be kept to a minimum. Ideally, studies should be population or hospital based

- The nature of the injuries should be adequately described. Common injury severity measures should be included to enable comparison of injury severity among studies

- Time period of participant follow-up should be a minimum of 3 months and ideally longer. Pain outcomes should be measured at more than one time point

- The dependent variable selection and analytic method should be clearly described and be appropriate. To determine the strongest evidence on predictors, analyses should be multivariate based

- Consistent, well-validated outcome measures specifically developed for pain should be used. The inclusion of closely related measures potentially subject to collinearity should be avoided. Ideally, more than one pain measure should be included

- Important confounders must be included in the model

- The intended purpose of the model should be clearly explained. Is the model intended to be useful in clinical practice? Is the model intended to explain the relationship between each explanatory factor and chronic pain outcomes?

- Explanatory factors and measures should be clearly described, including the time point at which the variable was measured, how it was measured and in what form it was entered into the model (did the variable require transformation?). There should be an adequate number of participants in the study sample with respect to the number of risk factors being entered into the model. The choice of explanatory factors should be based on a conceptual framework

- The methods for building multivariate models should be appropriate. The process and rationale for explanatory factor selection and model building should be clearly described including testing for: correlations between variables; multicollinearity; statistical interactions; and tests of normality of residuals, the use of stepwise model building methods and whether the reported model is a main effects model

- The extent of missing data and loss to follow-up should be reported

- The reporting of models should include confidence intervals around odds ratios and regression coefficients. The number of predictor variables that were included in the model should be indicated and the effect sizes for all factors included in multivariate models should be reported

\section{CONCLUSION}

The present review demonstrates that many people who have sustained acute orthopedic trauma experience persisting pain outcomes six months to seven years postinjury. Other than the role of education, high pain intensity, female sex, older age and preinjury anxiety and depression, there is currently insufficient evidence on prognostic variables to enable the early identification of acute orthopedic trauma patients at the greatest risk of experiencing chronic pain outcomes. Additional research in this area would be of considerable importance, not only in terms of increasing our understanding of the etiological risk factors for persisting pain in the setting of acute trauma, but also in advancing health care delivery to improve rehabilitation outcomes. Future research should focus on more methodologically rigorous, prospective studies.

FINANCIAL SUPPORT: Fiona Clay was supported by a National Health and Medical Research Council Scholarship.

CONFLICT OF INTEREST: All authors declare no conflict of interest.

\section{APPENDIX 1}

Ovid MEDLINE search strategy for the identification of relevant publications

\begin{tabular}{|c|c|}
\hline Search term & Number of articles identified \\
\hline 1 exp Pain/ & $(139669)$ \\
\hline 2 exp pain measurement/ & $(38283)$ \\
\hline 3 pain.mp. & $(227255)$ \\
\hline 4 pain prevalence.mp. & $(187)$ \\
\hline 5 pain severity.mp. & $(1364)$ \\
\hline 6 severity of pain.mp. & $(870)$ \\
\hline 7 prevalence of pain.mp. & $(338)$ \\
\hline 8 or/1-7 & $(250574)$ \\
\hline 9 exp risk/ & $(471327)$ \\
\hline 10 exp risk factors/ & $(328910)$ \\
\hline 11 risk factor*.mp. & $(408494)$ \\
\hline 12 exp probability/ & $(534487)$ \\
\hline 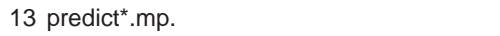 & $(490969)$ \\
\hline 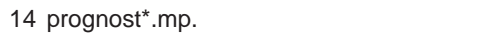 & $(86651)$ \\
\hline 15 determin*.mp. & $(1165474)$ \\
\hline 16 Or/9-15 & $(1983787)$ \\
\hline 17 exp wounds and injuries/ & $(524046)$ \\
\hline 18 exp dislocations/ & (9353) \\
\hline 19 exp hip injuries/ & $(6996)$ \\
\hline 20 exp leg injuries/ & $(26153)$ \\
\hline 21 fracture*.mp. & $(81129)$ \\
\hline 22 upper extremit*.mp. & $(9273)$ \\
\hline 23 lower extremit*.mp. & $(17957)$ \\
\hline 24 exp upper extremity/ & (49799) \\
\hline 25 exp lower extremityl & $(43310)$ \\
\hline 26 Or/17-25 & $(213311)$ \\
\hline 27 exp follow-up studies/ & $(241180)$ \\
\hline 28 exp prospective studies/ & $(206056)$ \\
\hline 29 exp retrospective studies/ & $(270313)$ \\
\hline 3027 or 28 or 29 & $(632917)$ \\
\hline 318 and 16 and 26 and 30 & (2189) \\
\hline 32 limit 31 to (english language and humans) & $(2029)$ \\
\hline 33 limit 32 to (adults $19-64$ years) & $(1784)$ \\
\hline 34 limit 33 to "prognosis" filter (sensitivity) & $(1060)$ \\
\hline 35 pain.tw. & (193131) \\
\hline 3634 and 35 & $(979)$ \\
\hline
\end{tabular}

3. Tunks ER, Crook J, Weir R. Epidemiology of chronic pain with psychological comorbidity: Prevalence, risk, course, and prognosis. Can J Psychiatry. 2008;53:224-34.

4. Access Economics. The High Price of Pain: The Economic Impact of Persistent Pain in Australia. Sydney: MBF Foundation, 2007:9-11. 
5. Dunstan DA, Covic T. Compensable work disability management: A literature review of biopsychosocial perspectives. Aust Occup Ther J 2006;53:67-77.

6. Bradley C, Harrison J. Descriptive Epidemiology of Traumatic Fractures in Australia. Canberra: Australian Institute of Health and Welfare, 2004.

7. Harris IA, Young JM, Rae H, Jalaludin BB, Solomon MJ. Factors associated with back pain after physical injury: A survey of consecutive major trauma patients. Spine 2007;32:1561-5.

8. Scholten-Peeters GG, Verhagen AP, Bekkering GE, et al. Prognostic factors of whiplash-associated disorders: A systematic review of prospective cohort studies. Pain 2003;104:303-22.

9. Carroll LJ, Hogg-Johnson S, van der Velde G, et al. Course and prognostic factors for neck pain in the general population: Results of the Bone and Joint Decade 2000-2010 Task Force on Neck Pain and Its Associated Disorders. Spine 2008;33:S75-82.

10. Ehde DM, Jensen MP, Engel JM, Turner JA, Hoffman AJ, Cardenas DD. Chronic pain secondary to disability: A review. Clin J Pain 2003;19:3-17.

11. Manchikanti L, Singh V, Datta S, Cohen SP, Hirsch JA; American Society of Interventional Pain Physicians. Comprehensive review of epidemiology, scope, and impact of spinal pain. Pain Physician 2009;12:E35-70.

12. Dobscha SK, Clark ME, Morasco BJ , Freeman M, Campbell R, Helfand M. Systematic review of the literature on pain in patients with polytrauma including traumatic brain injury. Pain Med 2009;10:1200-17.

13. Maas AI, Lingsma HF; IMPACT Study Group. New approaches to increase statistical power in TBI trials: Insights from the IMPACT study. Acta Neurochir Suppl 2008;101:119-24.

14. Roozenbeek B, Maas AI, Lingsma HF, et al. Baseline characteristics and statistical power in randomized controlled trials: Selection, prognostic targeting, or covariate adjustment? Crit Care Med 2009;37:2683-90.

15. Haddon W Jr. Advances in the epidemiology of injuries as a basis for public policy. Public Health Rep 1980;95:411-21.

16. National Centre for Classification in Health. The International Statistical Classification of Disease and Related Health ProblemsAustralian Modification (ICD-10-AM), 6th edn - Tenth revision. Sydney: National Centre for Classification in Health.

17. American Academy of Orthopaedic Surgeons. Orthopaedics. 2010; $<$ http://orthoinfo.aaos.org/topic.cfm?topic=A00099. (Accessed July 7, 2010).

18. Rothman K. Epidemiology: An Introduction. New York: Oxford University Press, 2002:71.

19. IASP Subcommitee on Taxonomy. Classification of chronic pain. Description of chronic pain syndromes and definition of pain terms. Pain Suppl 1986;3:S1-226.

20. Ehde DM, Czerniecki JM, Smith DG, Campbell KM, Edwards WT, Jensen MP. Chronic phantom sensations, phantom pain, residual limb pain, and other regional pain after lower limb amputation. Arch Phys Med Rehabil 2000;81:1039-44.

21. Vles WJ, Steyerberg EW, Essink-Bot ML, et al. Prevalence and determinants of disabilities and return to work after major trauma J Trauma. 2005;58:126-35.

22. Hayden JA, Cote P, Bombardier C. Evaluation of the quality of prognosis studies in systematic reviews. Ann Intern Med 2006;144:427-37.

23. Sackett DL, Richardon WS, Rosenberg W, Haynes RB. EvidenceBased Medicine. Edinburgh: Churchill Livingstone, 2000.

24. Clay FJ, Newstead SV, McClure RJ. A systematic review of early prognostic factors for return to work following acute orthopaedic trauma. Injury 2010;41:787-803.

25. Andrew NE, Gabbe BJ, Wolfe R, Williamson OD, Richardson MD, Edwards ER. Twelve-month outcomes of serious orthopaedic sport and active recreation-related injuries admitted to Level 1 trauma centers in Melbourne, Australia. Clin J Sport Med 2008;18:387-93.

26. Williamson OD, Gabbe BJ, Cameron PA, Edwards ER, Richardson MR. Predictors of moderate or severe pain 6 months after orthopaedic injury: A prospective cohort study. J Orthop Trauma 2009;23:139-44.

27. Ulvik A, Kvale R, Wentzel-Larsen T, Flaatten H. Quality of life 2-7 years after major trauma. Acta Anaesthesiol Scand 2008;52:195-201.

28. Jenewein J, Moergeli H, Wittmann L, Buchi S, Kraemer B, Schynder U. Development of chronic pain following severe accidental injury. Results of a 3-year follow-up study. J Psychosom Res 2009;66:119-26.

29. Holtslag HR, van Beeck EF, Lindeman E, Leenen LP. Determinants of long-term functional consequences after major trauma. J Trauma 2007;62:919-27.

30. Rivara FP, Mackenzie EJ, Jurkovich GJ, Nathens AB, Wang J, Scharfstein DO. Prevalence of pain in patients 1 year after major trauma. Arch Surg 2008;143:282-7; discussion 8.

31. Holmes A, Williamson O, Hogg M, et al. Predictors of pain severity 3 months after serious injury. Pain Med 2010;11:990-1000.

32. Hours M, Bernard M, Charnay P, et al. Functional outcome after road-crash injury: Description of the ESPARR victims cohort and 6-month follow-up results. Accid Anal Prev 2010;42:412-21.

33. Hoffman JM, Pagulayan KF, Zawaideh N, Dikmen S, Temkin N, Bell KR. Understanding pain after traumatic brain injury: Impact on community participation. Am J Phys Med Rehabil 2007;86:962-9.

34. Castillo RC, MacKenzie EJ, Wegener ST, Bosse MJ; LEAP Study Group. Prevalence of chronic pain seven years following limb threatening lower extremity trauma. Pain 2006;124:321-9

35. Baker SP, O'Neill B, Haddon W Jr, Long WB. The injury severity score: A method for describing patients with multiple injuries and evaluating emergency care. J Trauma 197;14:187-96.

36. Engel $\mathrm{G}$. The need for a new medical model: A challenge for biomedicine. Fam Syst Med 1992;6:523-7.

37. Turk DC. A diathesis-stress model of chronic pain and disability following traumatic injury. Pain Res Manag 2002;7:9-19.

38. Pincus T, Burton AK, Vogel S, Field AP. A systematic review of psychological factors as predictors of chronicity/disability in prospective cohorts of low back pain. Spine 2002;27:E109-20.

39. Turk DC, Rudy TE. Towards a comprehensive assessment of chronic pain patients. Behav Res Ther 1987;25:237-49.

40. Karoly P, Jensen MP. Multimethod Assessment of Chronic Pain. New York: Pergamon, 1987.

41. Jensen MP, Karoly P. Measurement of cancer pain via patient selfreporting. In: Chapman CR, Foley K, eds. Current and Emerging Issues in Research on Cancer Pain. Philadelphia: Lippincott-Raven 1993. <www.painresearch.utah.edu/cancerpain/ch13.html> (Accessed January 7, 2010).

42. Eich E, Reeves JL, Jaeger B, Graff-Radford B. Memory for pain: Relation between past and present pain intensity. Pain 1985;23:375-9.

43. Linton SJ. Occupational psychological factors increase the risk for back pain: A systematic review. J Occup Rehabil 2001;11:53-66.

44. Côté P, van der Velde G, Cassidy JD, et al. The burden and determinants of neck pain in workers: Results of the Bone and Joint Decade 2000-2010 Task Force on Neck Pain and Its Associated Disorders. Spine 2008;33(4 Suppl):S60-74.

45. Stroup DF, Berlin JA, Morton SC, et al. Meta-analysis of observational studies in epidemiology: A proposal for reporting. Meta-analysis Of Observational Studies in Epidemiology (MOOSE) group. JAMA 2000;283:2008-12. 


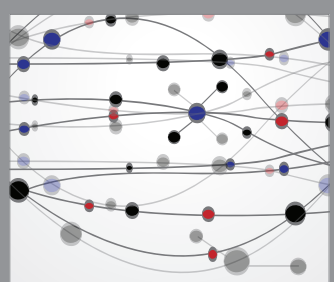

The Scientific World Journal
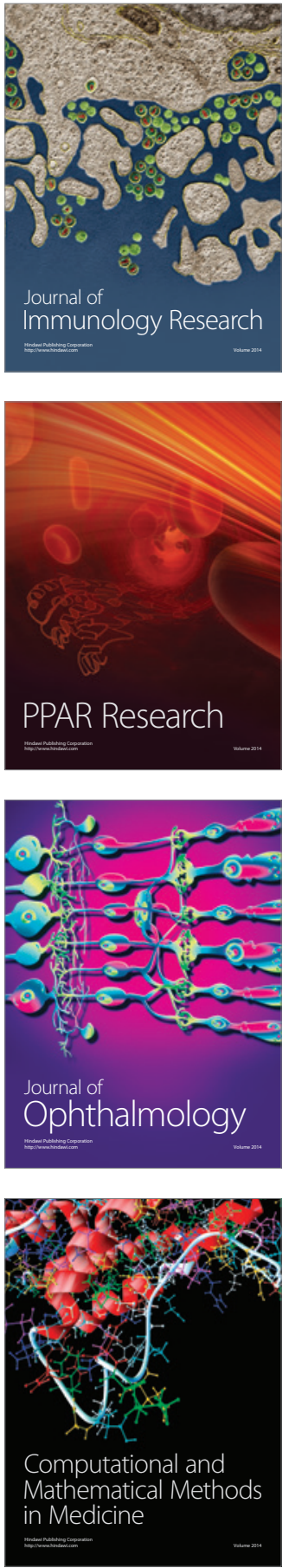

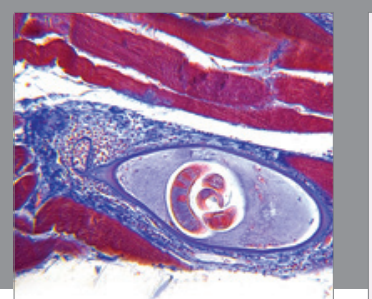

Gastroenterology Research and Practice

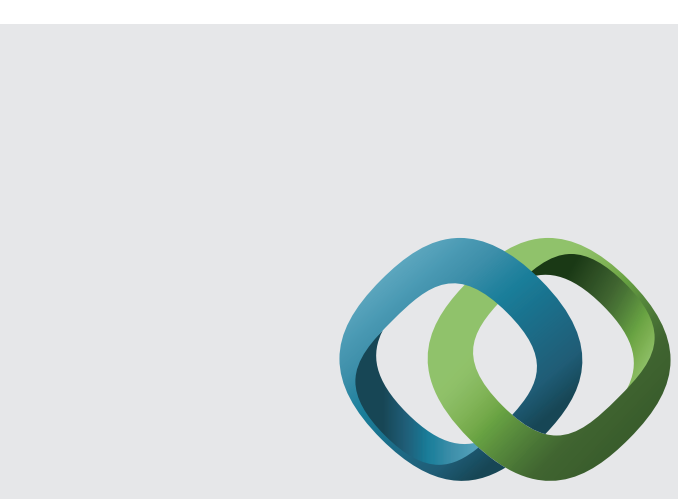

\section{Hindawi}

Submit your manuscripts at

http://www.hindawi.com
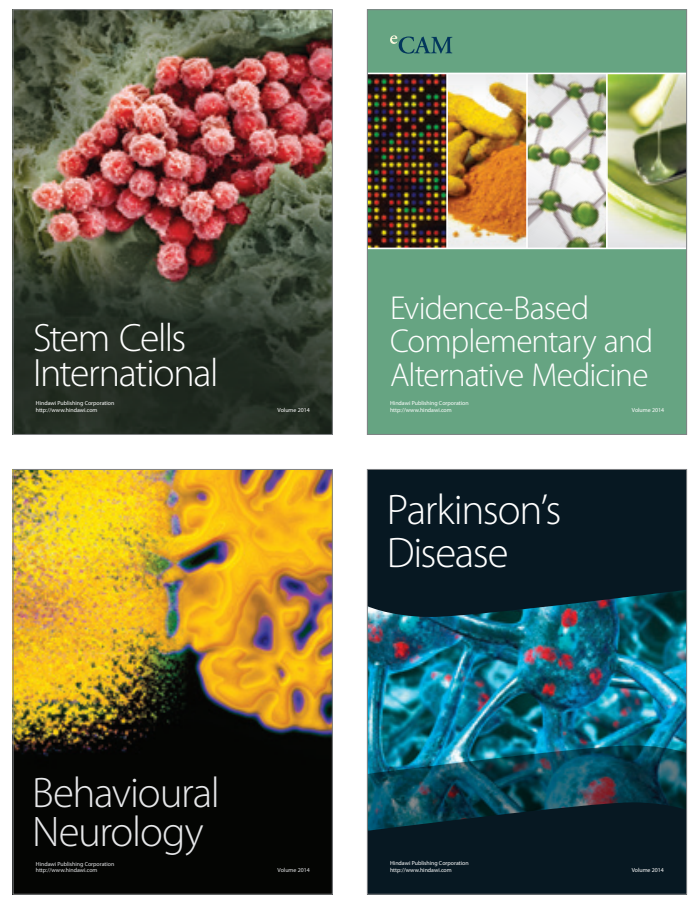
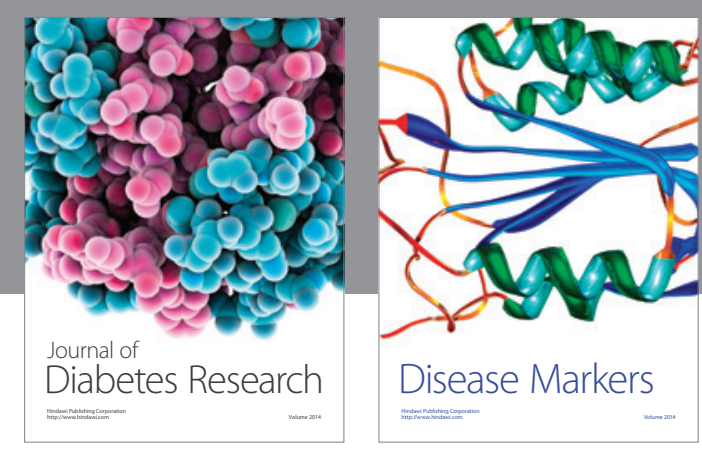

Disease Markers
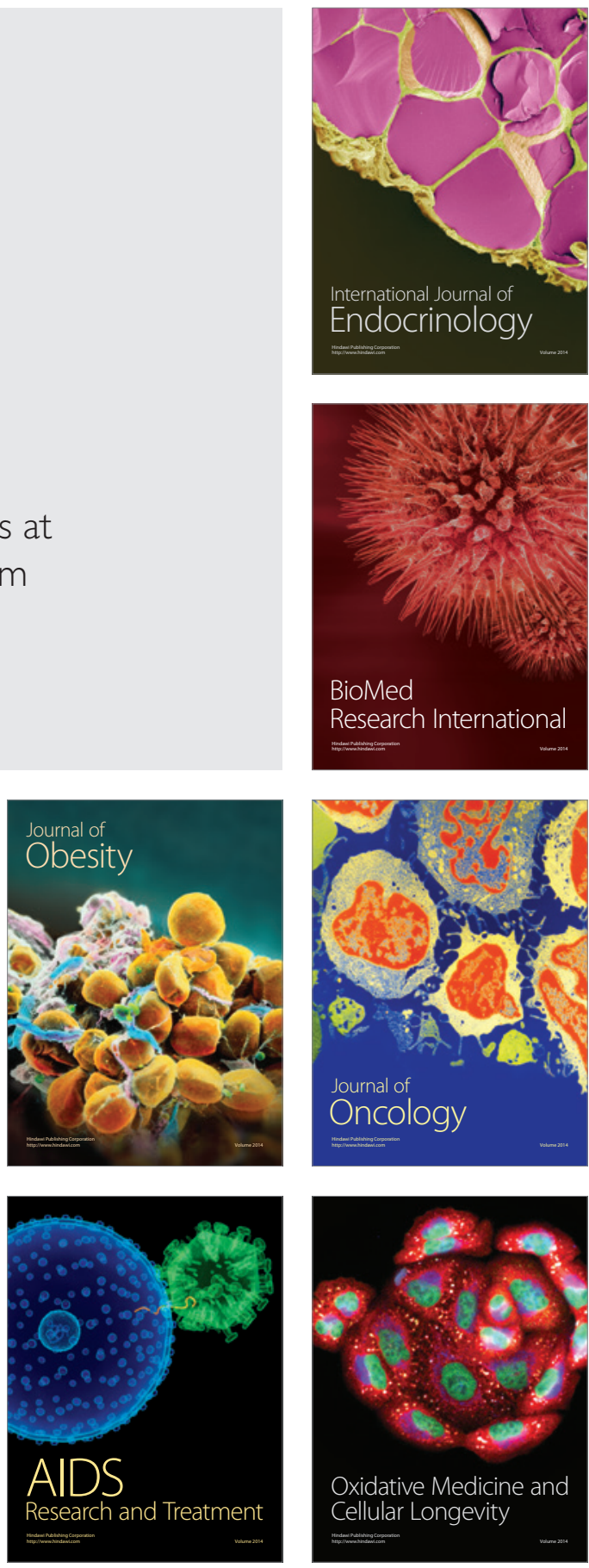